\title{
Review Article \\ The Consequences of Chorioamnionitis: Preterm Birth and Effects on Development
}

\author{
Robert Galinsky, ${ }^{1}$ Graeme R. Polglase, ${ }^{1,2}$ Stuart B. Hooper, ${ }^{1,2}$ \\ M. Jane Black, ${ }^{3}$ and Timothy J. M. Moss ${ }^{1,2}$ \\ ${ }^{1}$ The Ritchie Centre, Monash Institute of Medical Research, Monash University, P.O. Box 5418, Clayton, VIC 3168, Australia \\ ${ }^{2}$ Department of Obstetrics and Gynecology, Monash University, Clayton, VIC 3168, Australia \\ ${ }^{3}$ Department of Anatomy and Developmental Biology, Monash University, Clayton, VIC 3800, Australia
}

Correspondence should be addressed to Robert Galinsky; r.galinsky@auckland.ac.nz

Received 29 October 2012; Revised 28 January 2013; Accepted 10 February 2013

Academic Editor: Jeffrey Keelan

Copyright (C) 2013 Robert Galinsky et al. This is an open access article distributed under the Creative Commons Attribution License, which permits unrestricted use, distribution, and reproduction in any medium, provided the original work is properly cited.

\begin{abstract}
Preterm birth is a major cause of perinatal mortality and long-term morbidity. Chorioamnionitis is a common cause of preterm birth. Clinical chorioamnionitis, characterised by maternal fever, leukocytosis, tachycardia, uterine tenderness, and preterm rupture of membranes, is less common than subclinical/histologic chorioamnionitis, which is asymptomatic and defined by inflammation of the chorion, amnion, and placenta. Chorioamnionitis is often associated with a fetal inflammatory response. The fetal inflammatory response syndrome (FIRS) is defined by increased systemic inflammatory cytokine concentrations, funisitis, and fetal vasculitis. Clinical and epidemiological studies have demonstrated that FIRS leads to poor cardiorespiratory, neurological, and renal outcomes. These observations are further supported by experimental studies that have improved our understanding of the mechanisms responsible for these outcomes. This paper outlines clinical and experimental studies that have improved our current understanding of the mechanisms responsible for chorioamnionitis-induced preterm birth and explores the cellular and physiological mechanisms underlying poor cardiorespiratory, neural, retinal, and renal outcomes observed in preterm infants exposed to chorioamnionitis.
\end{abstract}

\section{Preterm Birth}

Preterm birth poses a major challenge for perinatal medicine, contributing to over $70 \%$ of perinatal mortality in developed countries (excluding deaths associated with congenital defects) [1-4]. Infants that survive preterm birth are more likely to suffer cardiorespiratory problems, mental retardation, cerebral palsy, and vision and hearing impairment, when compared to infants born at term [5].

Preterm birth is subcategorised according to gestational age at delivery: infants born preterm are delivered before 37 completed weeks of gestation. Late preterm births include infants delivered between 34 and 36 weeks and 6 days of gestation. Moderate preterm births are of infants delivered between 32 and 33 weeks and 6 days of gestation [4]. Infants born very preterm are delivered before 32 completed weeks; and infants born extremely preterm are delivered before 28 completed weeks of gestation [6].
Survival of extremely preterm infants has improved over the past decade, with the threshold of viability (defined as the gestational age at which $50 \%$ of infants survive) falling to less than 24 weeks [7]. Improved survival is a direct result of advances in perinatal care that include the use of antenatal glucocorticoids for precocious maturation of fetal organs, postnatal surfactant therapy for optimizing lung function, and the use of less injurious neonatal resuscitation strategies such as continuous positive airway pressure and noninjurious positive pressure ventilation [7-12].

The incidence of premature birth in developed countries varies from 7.6 to $12 \%$ of all births [13-15], whilst in many lowto-middle-income countries the incidence of preterm births is $\geq 15 \%$ of all births [14]: alarmingly, the incidence continues to rise $[14,15]$. The World Health Organisation estimates there are 15 million preterm births globally and 1 million direct fatalities annually [4]. 
Data from the United States indicate that the annual cost of neonatal care for preterm babies is US\$6 billion annually $[10,16]$, whilst the estimated societal economic impact is $\sim$ US $\$ 26.6$ billion [17]. The cost of caring for individual infants varies according to their gestational age [18], with care for an extremely preterm infant reaching US\$250,000 [10].

1.1. Etiology of Preterm Birth. There are a number of known contributors to premature birth [19], including the following:

(i) spontaneous preterm labour,

(ii) multiple pregnancy,

(iii) assisted reproduction,

(iv) preterm prelabour rupture of membranes,

(v) hypertensive disorders of pregnancy (e.g., preeclampsia),

(vi) intrauterine growth restriction,

(vii) antepartum haemorrhage,

(viii) miscellaneous (e.g., cervical incompetence, uterine malformations),

(ix) intrauterine inflammation/Chorioamnionitis.

Intrauterine inflammation most commonly presents as chorioamnionitis, which is defined as inflammation (caused usually by bacterial infection) of the chorion, amnion, and placenta. Intrauterine inflammation is one of the most common antecedents of premature birth [20].

The incidence of intrauterine inflammation is inversely related to gestational age, such that it is implicated in the majority of extremely preterm births and $16 \%$ of preterm births at 34 weeks [21, 22]. Microbiological studies indicate that intrauterine inflammation is associated with approximately $25-40 \%$ of all preterm births [20, 23, 24]. This is likely to be a conservative estimate due to the difficulty associated with detecting chorioamnionitis using conventional culture techniques [20].

1.2. Chorioamnionitis. Chorioamnionitis may manifest as a clinical condition defined by maternal fever, leukocytosis, tachycardia, uterine tenderness, and preterm rupture of membranes $[25,26]$. The diagnosis of clinical chorioamnionitis is most commonly made during labour near or at term. Highly virulent organisms likely cause clinical chorioamnionitis [27]. Before 30 weeks of gestation, clinical chorioamnionitis is usually diagnosed after attempting to delay preterm delivery or with preterm prolonged rupture of the fetal membranes [27].

Alternatively, chorioamnionitis can be subclinical, which is considered the most common manifestation and is defined histologically by inflammation of the chorion, amnion, and placenta $[26,28]$. Histological chorioamnionitis is associated with organisms considered to be of low virulence. Deliveries prior to 30 weeks of gestation are typically associated with histological chorioamnionitis [22]. Histological diagnosis occurs after delivery and is based on a semiquantitative assessment of inflammatory cells in the chorioamniotic membranes, umbilical cord (in cross-section), and placental disc. However, variability in the assessment criteria for the diagnosis of histological chorioamnionitis exists within the literature [29]. This may influence the results of studies of histological chorioamnionitis, preterm delivery, and outcomes.

The majority of fetuses exposed to chorioamnionitis develop a systemic inflammatory response known as the fetal inflammatory response syndrome (FIRS) [30, 31]. This is due to the fetus being in direct contact with infected amniotic fluid and/or inflammatory cell transfer from the uteroplacental circulation. FIRS can itself be categorised as clinical or subclinical. Clinical FIRS is defined by a fetal plasma [interleukin-6] $>11 \mathrm{pg} / \mathrm{mL}$ [32], whilst subclinical FIRS is defined histologically by funisitis and fetal vasculitis [31].

1.3. Animal Models of Chorioamnionitis/Intrauterine Inflammation. Intrauterine inflammation can be produced in experimental animals by exposing the fetus to lipopolysaccharide (LPS), derived from the outer cell wall of gramnegative bacteria. LPS is capable of inducing an inflammatory cascade (which is the dominant feature of clinical and subclinical chorioamnionitis), in the absence of bacterial infection.

Intracervical LPS administration to pregnant rats and rabbits has been used to model clinical chorioamnionitis $[33,34]$. Injection of LPS into the cervix causes high-grade placental inflammation $[33,34]$ associated with a maternal systemic inflammatory response that extends to the fetus and causes moderate to high rates of fetal loss [34-37]. The consequences of this experimental intervention mimic the most severe forms of clinical chorioamnionitis.

Other models of clinical chorioamnionitis include intravenous and intraperitoneal administration of LPS to pregnant animals. Intra-venous administration of LPS to pregnant sheep causes maternal pyrexia, septicaemia, and increased uterine contractility [38]. The effects on the fetus include systemic inflammation, increased serum cortisol levels, preterm delivery, and death [38, 39]. Direct intravenous administration of LPS to fetal sheep causes a high-grade FIRS that results in almost a $50 \%$ premature death rate [40]. In mice, maternal intravenous LPS exposure causes systemic and placental inflammation and altered placental vascular function $[41,42]$. Fetal demise due to administration of LPS to pregnant mice is dose dependant [42].

Intraperitoneal injection of LPS to pregnant rodents elicits a maternal systemic inflammatory response that causes placental inflammation, FIRS [43-45], and, in some cases, fetal death [46]. Interestingly, rats seem to be more resistant to inflammation-induced preterm birth than mice [46].

In sheep, rabbits and rodents, subclinical chorioamnionitis/intrauterine inflammation can been induced by injecting LPS into the amniotic cavity [47-49]. This does not present with clinical symptoms in the pregnant animal and causes a low-grade FIRS that is usually tolerated without fetal demise $[47,50,51]$.

1.4. Microbial Invasion of the Amniotic Cavity. Microbiota may invade the amniotic cavity via several pathways, outlined 
previously $[20,23,52]$. The most common mode of invasion involves microbes ascending from the vagina and/or cervix, resulting in an initial restricted invasion of the amniotic cavity. Microbes proliferate in the amniotic fluid and subsequently invade the amnion. In severe cases choriodecidual invasion may occur [53]. Thus, microbial invasion of the amniotic cavity precedes widespread infection of the chorioamniotic membranes. Other modes of microbial invasion of the amniotic cavity include contamination during invasive obstetric procedures such as amniocentesis or chorionic villous sampling; haematogenous dissemination through the placenta; and retrograde invasion from the peritoneal cavity through the fallopian tubes.

Traditionally, the microorganisms most commonly associated with infection of the amniotic cavity were species of Ureaplasma and Mycoplasma such as Ureaplasma urealyticum, Ureaplasma parvum, and Mycoplasma hominis [54, 55]. Due to recent advances in microbial detection, the range of microbial colonies in the amniotic cavity is now regarded as more diverse. Fusobacterium, Sneathia, and Leptotrichia have each been identified as novel and highly prevalent bacterial antecedents of chorioamnionitis [56, 57]. Furthermore a distinct difference in the prevalence/distribution of bacterial taxa exists between women that deliver preterm with intact membranes versus women that deliver preterm with premature rupture of membranes [56].

Whilst there is a wide range of data describing the role of bacterial invasion of the intrauterine space in premature labour, data describing the role of viruses and fungi in premature labour are limited. There is some evidence demonstrating viral and fungal invasion of the amniotic cavity in the pathogenesis of intrauterine inflammation. Specifically, cytomegalovirus, parvovirus, adenovirus, and the fungal phenotype Candida albicans have been detected in amniotic fluid samples [58-60]. There are data to suggest pregnant women with hepatitis $B$ virus are at increased risk of premature labour $[61,62]$. Furthermore, intrauterine injection of polyinosiniccytidylic acid (Poly I:C), a viral mimetic, causes preterm birth in rodents [63], whereas no effects of intra-amniotic Poly I:C were observed in sheep [64].

1.5. Chorioamnionitis Causes an Inflammatory Cascade That Leads to Preterm Birth. Preterm labour may result from a fetal and/or maternal response to chorioamnionitis. Bacteria that invade the choriodecidual space release endotoxins and exotoxins, which are recognised by Toll-like receptors (TLRs) on the surface of leukocytes, and dendritic, epithelial, and trophoblast cells $[65,66]$. This activates transcription factors NF- $\kappa$ B, AP-1, and STAT which produce cytokines and chemokines such as interleukin (IL)-6, IL-1 $\alpha$, IL-1 $\beta$, IL- 8 , and tumour necrosis factor- $\alpha$ (TNF $\alpha$ ) within the decidua and the fetal membranes [23]. Inflammatory cytokines stimulate the production of prostaglandins and initiate neutrophil chemotaxis, infiltration, and activation, resulting in the synthesis and release of metalloproteases [54]. Prostaglandins stimulate uterine contractions while metalloproteases cause cervical ripening and degrade the chorioamniotic membranes causing them to rupture [67].
Prostaglandins produced in the amnion are normally inactivated by prostaglandin dehydrogenase released by the chorionic tissue, thus preventing prostaglandins reaching the myometrium and causing uterine contractions [23]. Infection of the chorion inhibits the activity of prostaglandin dehydrogenase, thereby allowing prostaglandins to reach the myometrium and cause premature contractions [68].

In human pregnancies affected by chorioamnionitis, FIRS increases the production of corticotrophin releasing hormone $(\mathrm{CRH})$ from both the fetal hypothalamus and the placenta [23]. Increased CRH causes the fetal adrenal glands to increase cortisol production, which stimulates placental prostaglandin synthesis and myometrial contractility [69]. However, in studies using a sheep model of histological chorioamnionitis that displays many characteristics of the human condition, Nitsos et al. [51] showed that increases in fetal cortisol levels are minimal and unlikely to impact on fetal development.

1.6. Chorioamnionitis Affects Multiple Organ Systems. Chorioamnionitis, together with the associated FIRS, is an antecedent of preterm labour and a major contributor to neonatal morbidity $[23,54,55,70,71]$. The consequences of intrauterine inflammation on fetal and neonatal cardiopulmonary, cerebral, and renal systems are described in the following sections.

1.6.1. Heart. Evidence from humans and experimental models of chorioamnionitis suggest intrauterine inflammation results in abnormal fetal cardiac function. In humans, intrauterine inflammation has been associated with increased left ventricular compliance/dilatation [72]; this is thought to be a compensatory mechanism for maintaining left ventricular output and is commonly observed in adult patients experiencing sepsis [73]. Human neonates born after exposure to inflammation/infection in utero exhibit reduced mean and diastolic blood pressure, effects which may contribute to the increased incidence of periventricular leukomalacia and cerebral palsy in neonates exposed to chorioamnionitis in utero [74].

These clinical observations are supported by animal studies that have demonstrated reduced descending aorta blood flow velocities in fetal rats following intracervical administration of LPS to pregnant dams [33]. In fetal mice intra-amniotic LPS exposure caused inflammation and impaired contractility and relaxation of the myocardial tissue [75]. Increased cardiac afterload and reduced cardiac output have also been observed in fetal mice after maternal LPS administration [41]. Abdulkadir et al. [33] demonstrated that chorioamnionitis induced by intracervical LPS exposure caused a reduction in heart rate in newborn rat pups. In vitro studies have demonstrated that treatment of immature cardiomyocytes with LPS for 72 hours stimulated the production of inflammatory molecules within the cardiomyocytes and caused cardiomyocyte loss that was reversible with NF- $\kappa \mathrm{B}$ inhibition [76]. Collectively these studies indicate that exposure to inflammation in utero not only impairs cardiac function but may also impair development of the myocardium, 
with likely long-term deleterious consequences. Given the evidence from human and animal studies, investigation of the long-term cardiovascular consequences of exposure to intrauterine inflammation is warranted.

1.6.2. Lungs. In 1996, Watterberg et al. [77] demonstrated that infants exposed to chorioamnionitis had a reduced risk of developing respiratory distress syndrome (RDS) and an increased risk of bronchopulmonary dysplasia (BPD). RDS is caused primarily by a lack of pulmonary surfactant and its incidence is inversely associated with gestational age at delivery [10]. It is characterised by tachypnoea, chest wall retraction, cyanosis, and a ground glass appearance of the chest on X-ray [78].

BPD is defined as the need for supplemental oxygen beyond one month of postnatal age $[79,80]$ and is most commonly observed in extremely preterm infants [79]. BPD is characterised by impaired vascularisation and alveolarization of the developing lung, whereby pulmonary microvascular angiogenesis is disrupted and alveoli are fewer in number and larger in size $[27,80]$. An increased risk of BPD in preterm neonates exposed to chorioamnionitis may be mediated by other postnatal events such as mechanical ventilation and oxygen exposure [80].

Since the initial description by Watterberg et al. [77], clinical data have accumulated to demonstrate that the relationship between chorioamnionitis, RDS, and BPD is more complex than initially described. Been et al. [81] demonstrated that infants diagnosed with chorioamnionitis and FIRS had an increased risk of developing RDS and were less responsive to surfactant treatment relative to infants diagnosed with chorioamnionitis but without FIRS. In contrast, infants diagnosed with chorioamnionitis but without accompanying FIRS had less severe RDS than infants who were not exposed to chorioamnionitis. Recent studies have been unable to demonstrate an independent association between chorioamnionitis and the development of BPD in preterm infants [82,83], likely because of the complex variety of prenatal inflammatory stimuli and their interaction with ventilatory management of neonates [84].

Animal studies clearly indicate that fetal lung development is altered by intrauterine inflammation. In rats, intraamniotic administration of inflammatory cytokines such as IL- 6 and IL-8 increases the expression of messenger RNA for surfactant proteins (SP) A, B, and C in the fetal lung [85]. The increase in surfactant protein production is thought to be associated with an increase in type 2 alveolar epithelial cells because in vivo and in vitro studies of fetal mice show that intra-amniotic LPS exposure increases type 2 alveolar epithelial cell numbers [86]. Consistent observations have been made in rabbits and sheep whereby intra-amniotic or intratracheal injection of IL- $1 \alpha$ or LPS resulted in increased mRNA expression of SP-A and -B in the fetal lungs [87-90]. We have recently demonstrated that the fetal lung response to intrauterine inflammation is mediated, at least in part, by prostaglandins [90].

In sheep, intrauterine inflammation causes pulmonary inflammation with increased mRNA levels of inflammatory cytokines IL- $1 \beta$, IL- 6 , and IL- 8 and chemokines IP-10 and MIG within 24 hours [50,91]. Reduced expression of microvascular markers (vascular endothelial growth factor (VEGF), VEGF receptor 2, endothelial nitric oxide synthase (eNOS), tyrosine protein kinase receptor (Tie-2), and platelet endothelial cell adhesion molecule (PECAM)) occurs between 1 and 4 days after LPS exposure [92].

Inflammation-induced alterations to fetal pulmonary vascular development include smooth muscle hypertrophy and deposition of collagen in the adventitial layer of pulmonary resistance arterioles [92]. We have recently observed that these alterations to the pulmonary vasculature are associated with an increase in pulmonary vascular resistance and subsequent reduction in pulmonary blood flow in the fetus at 2 and 4 days, respectively, after intra-amniotic LPS exposure [93].

Structural remodeling of the airspace occurs 7 days after intra-amniotic injection of LPS in sheep, resulting in the presence of fewer and larger alveoli (20\% decrease in alveolar number and 30\% increase in alveolar volume), and thinning of the alveolar epithelial layer [88].

One of the postnatal consequences of inflammationinduced vascular remodelling of the fetal lungs is persistent pulmonary hypertension of the newborn (PPHN). This condition is characterised by increased resistance to pulmonary blood flow and right-to-left shunting across the foramen ovale (FO) and ductus arteriosus (DA), resulting in decreased left ventricular output $[94,95]$. PPHN increases the risk of BPD and hypoxemia, but is also increased by BPD [96]. Preterm lambs exposed to a single injection of intra-amniotic LPS 7 days prior to delivery showed increased pulmonary vascular resistance and right-to-left shunting of blood through the DA within 30 minutes after delivery [97]. LPS exposure 2 or 4 days prior to delivery does not have such profound effects on pulmonary haemodynamics of preterm lambs, suggesting that the full extent of vascular remodelling had not occurred by that time [98]. Considering the pulmonary vascular and alveolar remodelling demonstrated in fetal lambs exposed to intra-amniotic LPS [88, 92], a causative link between chorioamnionitis, BPD, and PPHN becomes increasingly apparent.

1.6.3. Brain. In preterm infants, perinatal brain damage is a major cause of developmental delay and lifelong neurological impairments such as mental retardation, cerebral palsy, and learning, and behavioural deficits [99-101]. In the US, the estimated lifetime costs for persons born with mental retardation is $\$ 51.2$ billion and $\$ 11.5$ billion for persons born with cerebral palsy [102]. There is robust epidemiological evidence linking perinatal brain injury, in particular cerebral palsy, periventricular leukomalacia, and intraventricular haemorrhage, with intrauterine inflammation [25, 103-108]. Exposure to histological chorioamnionitis combined with impaired placental perfusion has been demonstrated to increase the risk of poor neurological and neurocognitive outcomes at 2 years of corrected age in children born very preterm [99]. Similar observations were made at 8 years of age in children exposed to severe histological chorioamnionitis [100]. Histological chorioamnionitis is also associated 
with an increased incidence of speech delay and hearing loss at 18 months of corrected age in infants born very preterm [101]. Furthermore, histological chorioamnionitis caused by bacterial and viral infection has been associated with an increased risk of autism spectrum disorders [109] and schizophrenia [110, 111]. Recent work suggests that persistent inflammation is responsible for phenotypic abnormalities observed in autism, whereas a latent inflammatory process in utero appears responsible for schizophrenia-specific brain and behavioural abnormalities [112].

A number of clinical studies have identified potential mechanisms for associations between chorioamnionitis and adverse neurological outcomes. A direct effect of immune activation is demonstrated by studies showing that intrauterine inflammation is linked with diffuse white matter injury in the brain of preterm neonates, due to activation of a systemic inflammatory cascade $[99,105-107,113]$.

Chorioamnionitis has been associated with impaired fetal and newborn cardiac function [74, 114], which may compromise brain blood flow. Lower blood pressures and higher concentrations of inflammatory mediators have been demonstrated in the systemic circulation in very low birth weight infants exposed to chorioamnionitis $[107,115,116]$. Yanowitz et al. [117] demonstrated that cerebral oxygen delivery is altered in prematurely born infants exposed to chorioamnionitis. These observations suggest that cerebral blood flow and/or autoregulation of cerebral blood flow are impaired in infants born following exposure to chorioamnionitis.

Impaired cerebral autoregulation is considered one of the main contributors to brain injury in the preterm neonate [118, $119]$ and has previously been demonstrated in preterm infants during the first 120 hours after birth [120, 121]. Impaired cerebral autoregulation may be more prevalent in neonates born after exposure to intrauterine inflammation [115, 119, $122,123]$; however there are limited data that directly support this contention.

Data from animal experiments are consistent with human studies in showing effects of intrauterine inflammation on the developing brain. Rabbit pups exposed to a single intraamniotic injection of $E$. coli showed periventricular lesions documented in the form of karyorrhexis (nuclear fragmentation) of glial cells and reduced density and disorganization of white matter [124]. In fetal sheep, chronic administration of intra-amniotic LPS derived from E. coli resulted in damage to subcortical white matter in the form of astrocytosis and a reduction in oligodendrocyte number [125]. Intravenous administration of LPS to fetal lambs caused diffuse damage and focal PVL in white matter [126]. In the offspring of pregnant rats exposed to a single intraperitoneal injection of LPS, a decrease in myelination was observed, potentially due to reduced numbers and/or function of oligodendrocytes [127].

Recent experiments examining the effect of intrauterine inflammation on cerebral haemodynamics have shown that within 15 minutes after delivery carotid arterial blood flow and pressure are increased in preterm lambs 2 days after LPS exposure [98]. Additionally, carotid arterial pressure was shown to be increased 1 hour after preterm delivery of lambs
7 days after LPS exposure [97]. Such disturbances in cerebral haemodynamics may increase susceptibility to brain injury in the preterm neonate.

We have demonstrated an increase in inflammatory cytokine mRNA expression in the periventricular and subcortical white matter and periventricular vascular damage and haemorrhage, 48 to 96 hours after exposure to intraamniotic LPS [98], and increased cerebral perfusion after 4 and 5 days in preterm fetal sheep [93]. This finding is consistent with the observation that cerebral $\mathrm{DO}_{2}$ is increased in preterm fetal sheep exposed to intra-amniotic LPS, indicating an increased cerebral metabolic demand before birth [128].

Inflammatory cytokines released during the course of intrauterine inflammation have been suggested as a possible cause of cerebral injury observed in animal studies $[129,130]$. The potential mechanisms of inflammatory cytokine induced brain injury include the following:

(1) a direct effect on the cerebral vasculature causing cerebral hypoperfusion and ischemia [74, 131],

(2) activation of blood coagulators resulting in capillary thrombosis and necrosis of white matter [132],

(3) activation of microglia, causing a direct toxic effect on oligodendrocytes and myelin via microglial production of proinfammatory cytokines, neuronal loss and impaired neuronal guidance [133-135]. Microglial activation also generates free radicals that cause death of immature oligodendrocytes $[108,136]$,

(4) increased permeability of the blood brain barrier, allowing direct passage of microbial products and cytokines into the cerebral tissue [137-139].

1.6.4. Retina. Recent evidence suggests an association between chorioamnionitis and retinopathy of prematurity (ROP). Higher rates of ROP have been demonstrated in infants born to mothers with histological and clinical chorioamnionitis relative to mothers without chorioamnionitis [140-142]. Chorioamnionitis and the accompanying fetal inflammatory response syndrome may increase the risk of ROP by directly sensitising the developing retina to oxygen-induced changes in VEGF availability and subsequent vascular development and/or by causing systemic hypotension resulting in retinal hypoperfusion/ischemia $[143,144]$. Frequent, intermittent hypoxic events are associated with severe ROP [145]. These clinical data indicate a need for experimental studies to elucidate the pathophysiological mechanisms underlying the increased risk of ROP in infants exposed to chorioamnionitis.

1.6.5. Kidneys. Clinical data demonstrating an effect of chorioamnionitis on the developing kidney are limited. In a study of women with preterm premature rupture of membranes, FIRS was associated with oligohydramnios [146]. Since fetal urine production is a major component of amniotic fluid volume, this suggests a reduction in fetal renal function, perhaps as a consequence of redistributed blood flow away from the fetal kidneys [146]. Similar observations have been made in adult patients suffering from septicaemia, 
where oliguria is thought to be a manifestation of renal inflammation [147, 148]. Chorioamnionitis has been associated with renal and electrolyte abnormalities in preterm neonates treated with indomethacin, suggesting chorioamnionitis may adversely affect renal development [149].

Experimental evidence from our laboratory has demonstrated that preterm fetal sheep exposed to intrauterine inflammation have a reduction in nephron number of $\sim 20 \%$ [150]. This may predispose the preterm infant exposed to chorioamnionitis to impaired renal function during the neonatal period and an increased risk of hypertension and renal dysfunction later in life, in accordance with the Brenner hypothesis [151]. At this point in time the effects of intrauterine inflammation on renal development and function and how it leads to a reduction in the number of nephrons formed in the kidney are largely unknown. Further studies are required to determine the mechanisms underlying the inflammation-induced reduction in nephron number and the extent of the renal and cardiovascular consequences in the neonate and adult.

\section{Summary}

Available clinical, epidemiological, and experimental data indicate that chorioamnionitis plays a significant role in predisposing the preterm infant to multiple organ disease. Further investigation is required to improve our understanding of the mechanism(s) underlying the changes in development and function of the preterm cardiorespiratory, central nervous, visual, and renal systems. Improved antenatal screening for chorioamnionitis and identification of effective treatment strategies for preterm infants exposed to intrauterine inflammation will likely provide a better prognosis for infants at risk of multiple organ disease as a result of exposure to inflammation before birth.

\section{Acknowledgments}

The authors gratefully acknowledge funding support from the National Health and Medical Research Council and the Victorian Government's Operational Infrastructure Support Program.

\section{References}

[1] P. Laws, Z. Li, and E. A. Sullivan, Autralia's mothers and babies 2008, Perinatal Statistics Series no. 24 Cat no. PER 50, Australian Institute of Health and Welfare, Canberra, Australia, 2010.

[2] D. R. Mattison, K. Damus, E. Fiore, J. Petrini, and C. Alter, "Preterm delivery: a public health perspective," Paediatric and Perinatal Epidemiology, vol. 15, no. 2, pp. 7-16, 2001.

[3] J. A. Martin, B. E. Hamilton, P. D. Sutton, S. J. Ventura, F. Menacker, and S. Kirmeyer, "Births: final data for 2004," National Vital Statistics Reports, vol. 55, no. 1, pp. 1-101, 2006.

[4] C. P. Howson, M. V. Kinney, and J. E. Lawn, Eds., "March of dimes, PMNCH, save the children, WHO. Born too soon," The Global Action Report on Preterm Birth, WHO., Geneva, Switzerland, 2012.
[5] K. Flood and F. D. Malone, "Prevention of preterm birth," Seminars in Fetal \& Neonatal Medicine, vol. 17, pp. 58-63, 2012.

[6] J. Tucker and W. McGuire, "Epidemiology of preterm birth," British Medical Journal, vol. 329, no. 7467, pp. 675-678, 2004.

[7] K. L. Kyser, F. H. Morriss Jr., E. F. Bell, J. M. Klein, and J. M. Dagle, "Improving survival of extremely preterm infants born between 22 and 25 weeks of gestation," Obstetrics and Gynecology, vol. 119, pp. 795-800, 2012.

[8] J. A. Lemons, C. R. Bauer, W. Oh et al., "Very low birth weight outcomes of the National Institute of Child health and human development neonatal research network, January 1995 through December 1996. NICHD Neonatal Research Network," Pediatrics, vol. 107, no. 1, p. E1, 2001.

[9] V. Y. H. Yu and L. W. Doyle, "Regionalized long-term follow-up," Seminars in Neonatology, vol. 9, no. 2, pp. 135-144, 2004.

[10] T. J. M. Moss, "Respiratory consequences of preterm birth," Clinical and Experimental Pharmacology and Physiology, vol. 33, no. 3, pp. 280-284, 2006.

[11] G. L. Chu, J. Wang, Y. Xin, J. Zheng, R. X. Zheng, and D. Z. Bi, "Protective and curative effects of prophylactic administration of pulmonary surfactant on neonatal respiratory distress syndrome," National Medical Journal of China, vol. 86, no. 13, pp. 876-880, 2006.

[12] G. C. Liggins, "Premature delivery of foetal lambs infused with glucocorticoids," The Journal of Endocrinology, vol. 45, no. 4, pp. 515-523, 1969.

[13] S. Abeywardana, The Report of the Australian and New Zealand Neonatal Network, 2004, ANZNN, Sydney, Australia, 2006.

[14] H. Blencowe, S. Cousens, M. Z. Oestergaard et al., "National, regional, and worldwide estimates of preterm birth rates in the year 2010 with time trends since 1990 for selected countries: a systematic analysis and implications," The Lancet, vol. 379, pp. 2162-2172, 2012.

[15] H. H. Chang, J. Larson, H. Blencowe et al., "Preventing preterm births: analysis of trends and potential reductions with interventions in 39 countries with very high human development index," The Lancet, vol. 381, no. 9862, pp. 223-234, 2012.

[16] R. B. Russell, N. S. Green, C. A. Steiner et al., "Cost of hospitalization for preterm and low birth weight infants in the United States," Pediatrics, vol. 120, no. 1, pp. el-e9, 2007.

[17] T. Reuters, "The Cost of Prematurity and Complicated Deliveries to U.S. Employers," Report Prepared For the March of Dimes, 2008.

[18] J. M. Hodek, J. M. von der Schulenburg, and T. Mittendorf, "Measuring economic consequences of preterm birthmethodological recommendations for the evaluation of personal burden on children and their caregivers," Health Economics Review, vol. 1, no. 1, article 6, 2011.

[19] M. M. Slattery and J. J. Morrison, "Preterm delivery," The Lancet, vol. 360, no. 9344, pp. 1489-1497, 2002.

[20] R. L. Goldenberg, J. F. Culhane, J. D. Iams, and R. Romero, "Epidemiology and causes of preterm birth," The Lancet, vol. 371, no. 9606, pp. 75-84, 2008.

[21] M. M. Lahra, P. J. Beeby, and H. E. Jeffery, "Maternal versus fetal inflammation and respiratory distress syndrome: a 10-year hospital cohort study," Archives of Disease in Childhood, vol. 94, no. 1, pp. F13-F16, 2009.

[22] M. M. Lahra and H. E. Jeffery, "A fetal response to chorioamnionitis is associated with early survival after preterm birth," American Journal of Obstetrics and Gynecology, vol. 190, no. 1, pp. 147-151, 2004. 
[23] R. L. Goldenberg, J. C. Hauth, and W. W. Andrews, "Intrauterine infection and preterm delivery," The New England Journal of Medicine, vol. 342, no. 20, pp. 1500-1507, 2000.

[24] R. F. Lamont and S. R. Sawant, "Infection in the prediction and antibiotics in the prevention of spontaneous preterm labour and preterm birth," Minerva Ginecologica, vol. 57, no. 4, pp. 423-433, 2005.

[25] A. Leviton, N. Paneth, M. L. Reuss et al., "Maternal infection, fetal inflammatory response, and brain damage in very low birth weight infants," Pediatric Research, vol. 46, no. 5, pp. 566-575, 1999.

[26] H. Hagberg, U. B. Wennerholm, and K. Sävman, "Sequelae of chorioamnionitis," Current Opinion in Infectious Diseases, vol. 15, no. 3, pp. 301-306, 2002.

[27] A. H. Jobe, S. Kallapur, and T. J. M. Moss, "Inflammation/infection: effects on the fetal/newborn lung," in The Newborn Lung, Neonatology Questions and Controversies, E. Banclari and R. A. Polin, Eds., pp. P119-P140, Elsevier, Philadelphia, Pa, USA, 2008.

[28] R. M. Viscardi, C. K. Muhumuza, A. Rodriguez et al., "Inflammatory markers in intrauterine and fetal blood and cerebrospinal fluid compartments are associated with adverse pulmonary and neurologic outcomes in preterm infants," Pediatric Research, vol. 55, no. 6, pp. 1009-1017, 2004.

[29] C. Holzman, X. Lin, P. Senagore, and H. Chung, "Histologic chorioamnionitis and preterm delivery," American Journal of Epidemiology, vol. 166, no. 7, pp. 786-794, 2007.

[30] W. W. Andrews, R. L. Goldenberg, O. Faye-Petersen, S. Cliver, A. R. Goepfert, and J. C. Hauth, "The Alabama Preterm Birth study: polymorphonuclear and mononuclear cell placental infiltrations, other markers of inflammation, and outcomes in 23- to 32-week preterm newborn infants," American Journal of Obstetrics and Gynecology, vol. 195, no. 3, pp. 803-808, 2006.

[31] F. Gotsch, R. Romero, J. P. Kusanovic et al., "The fetal inflammatory response syndrome," Clinical Obstetrics and Gynecology, vol. 50, no. 3, pp. 652-683, 2007.

[32] R. Gomez, R. Romero, F. Ghezzi, Bo Hyun Yoon, M. Mazor, and S. M. Berry, "The fetal inflammatory response syndrome," American Journal of Obstetrics and Gynecology, vol. 179, no. 1, pp. 194-202, 1998.

[33] A. A. Abdulkadir, T. Kimimasa, M. J. Bell, T. A. MacPherson, B. B. Keller, and T. D. Yanowitz, "Placental inflammation and fetal hemodynamics in a rat model of chorioamnionitis," Pediatric Research, vol. 68, no. 6, pp. 513-518, 2010.

[34] R. A. Dombroski, D. S. Woodard, M. J. K. Harper, and R. S. Gibbs, "A rabbit model for bacteria-induced preterm pregnancy loss," American Journal of Obstetrics and Gynecology, vol. 163, no. 6, pp. 1938-1943, 1990.

[35] M. A. Elovitz and C. Mrinalini, "Animal models of preterm birth," Trends in Endocrinology and Metabolism, vol. 15, no. 10, pp. 479-487, 2004.

[36] E. Hirsch and H. Wang, "The molecular pathophysiology of bacterially induced preterm labor: insights from the murine model," Journal of the Society for Gynecologic Investigation, vol. 12, no. 3, pp. 145-155, 2005.

[37] L. Heddleston, R. S. McDuffie, and R. S. Gibbs, "A rabbit model for ascending infection in pregnancy: intervention with indomethacin and delayed ampicillin-sulbactam therapy," American Journal of Obstetrics and Gynecology, vol. 169, no. 3, pp. 708-712, 1993.

[38] P. L. Grigsby, J. J. Hirst, J. P. Scheerlinck, D. J. Phillips, and G. Jenkin, "Fetal responses to maternal and intra-amniotic lipopolysaccharide administration in sheep," Biology of Reproduction, vol. 68, no. 5, pp. 1695-1702, 2003.

[39] D. H. Schlafer, B. Yuh, G. L. Foley, T. H. Elssaser, D. Sadowsky, and P. W. Nathanielsz, "Effect of salmonella endotoxin administered to the pregnant sheep at 133-142 days gestation on fetal oxygenation, maternal and fetal adrenocorticotropic hormone and cortisol, and maternal plasma tumor necrosis factor $\alpha$ concentrations," Biology of Reproduction, vol. 50, no. 6, pp. 1297-1302, 1994.

[40] S. Y. S. Feng, T. Samarasinghe, D. J. Phillips et al., "Acute and chronic effects of endotoxin on cerebral circulation in lambs," American Journal of Physiology, vol. 298, no. 3, pp. R760-R766, 2010.

[41] S. Rounioja, J. Räsänen, M. Ojaniemi, V. Glumoff, H. AutioHarmainen, and M. Hallman, "Mechanism of acute fetal cardiovascular depression after maternal inflammatory challenge in mouse," American Journal of Pathology, vol. 166, no. 6, pp. 1585-1592, 2005.

[42] S. J. Renaud, T. Cotechini, J. S. Quirt, S. K. MacdonaldGoodfellow, M. Othman, and C. H. Graham, "Spontaneous pregnancy loss mediated by abnormal maternal inflammation in rats is linked to deficient uteroplacental perfusion," Journal of Immunology, vol. 186, no. 3, pp. 1799-1808, 2011.

[43] K. Belarbi, C. Arellano, R. Ferguson, T. Jopson, and S. Rosi, "Chronic neuroinflammation impacts the recruitment of adultborn neurons into behaviorally relevant hippocampal networks," Brain, Behavior, and Immunity, vol. 26, pp. 18-23, 2012.

[44] H. Ashdown, Y. Dumont, M. Ng, S. Poole, P. Boksa, and G. $\mathrm{N}$. Luheshi, "The role of cytokines in mediating effects of prenatal infection on the fetus: implications for schizophrenia," Molecular Psychiatry, vol. 11, no. 1, pp. 47-55, 2006.

[45] D. A. Gayle, R. Beloosesky, M. Desai, F. Amidi, S. E. Nuñez, and M. G. Ross, "Maternal LPS induces cytokines in the amniotic fluid and corticotropin releasing hormone in the fetal rat brain," American Journal of Physiology, vol. 286, no. 6, pp. R1024-R1029, 2004.

[46] Y. Kohmura, T. Kirikae, F. Kirikae, M. Nakano, and I. Sato, "Lipopolysaccharide (LPS)-induced intra-uterine fetal death (IUFD) in mice is principally due to maternal cause but not fetal sensitivity to LPS," Microbiology and Immunology, vol. 44, no. 11, pp. 897-904, 2000.

[47] J. P. Newnham, T. J. Moss, B. W. Kramer, I. Nitsos, M. Ikegami, and A. H. Jobe, "The fetal maturational and inflammatory responses to different routes of endotoxin infusion in sheep," American Journal of Obstetrics and Gynecology, vol. 186, no. 5, pp. 1062-1068, 2002.

[48] M. A. Elovitz, A. G. Brown, K. Breen et al., "Intrauterine inflammation, insufficient to induce parturition, still evokes fetal and neonatal brain injury," International Journal of Developmental Neuroscience, vol. 29, pp. 663-671, 2011.

[49] K. Bry and U. Lappalainen, "Intra-amniotic endotoxin accelerates lung maturation in fetal rabbits," Acta Paediatrica, International Journal of Paediatrics, vol. 90, no. 1, pp. 74-80, 2001.

[50] B. W. Kramer, T. J. Moss, K. E. Willet et al., "Dose and time response after intraamniotic endotoxin in preterm lambs," American Journal of Respiratory and Critical Care Medicine, vol. 164, no. 6, pp. 982-988, 2001.

[51] I. Nitsos, T. J. M. Moss, M. L. Cock, R. Harding, and J. P. Newnham, "Fetal responses to intra-amniotic endotoxin in sheep," Journal of the Society for Gynecologic Investigation, vol. 9, no. 2, pp. 80-85, 2002. 
[52] L. F. Gonçalves, T. Chaiworapongsa, and R. Romero, "Intrauterine infection and prematurity," Mental Retardation and Developmental Disabilities Research Reviews, vol. 8, no. 1, pp. 3-13, 2002.

[53] M. J. Kim, R. Romero, M. T. Gervasi et al., "Widespread microbial invasion of the chorioamniotic membranes is a consequence and not a cause of intra-amniotic infection," Laboratory Investigation, vol. 89, no. 8, pp. 924-936, 2009.

[54] R. Romero, J. Espinoza, T. Chaiworapongsa, and K. Kalache, "Infection and prematurity and the role of preventive strategies," Seminars in Neonatology, vol. 7, no. 4, pp. 259-274, 2002.

[55] R. Romero, J. Espinoza, L. F. Gonçalves, J. P. Kusanovic, L. A. Friel, and J. K. Nien, "Inflammation in preterm and term labour and delivery," Seminars in Fetal and Neonatal Medicine, vol. 11, no. 5, pp. 317-326, 2006.

[56] D. B. DiGiulio, "Diversity of microbes in amniotic fluid," Seminars in Fetal \& Neonatal Medicine, vol. 17, pp. 2-11, 2012.

[57] D. B. DiGiulio, R. Romero, J. P. Kusanovic et al., "Prevalence and diversity of microbes in the amniotic fluid, the fetal inflammatory response, and pregnancy outcome in women with preterm pre-labor rupture of membranes," American Journal of Reproductive Immunology, vol. 64, no. 1, pp. 38-57, 2010.

[58] K. D. Wenstrom, W. W. Andrews, N. E. Bowles, J. A. Towbin, J. C. Hauth, and R. L. Goldenberg, "Intrauterine viral infection at the time of second trimester genetic amniocentesis," Obstetrics and Gynecology, vol. 92, no. 3, pp. 420-424, 1998.

[59] C. Liesnard, C. Donner, F. Brancart, F. Gosselin, M. L. Delforge, and F. Rodesch, "Prenatal diagnosis of congenital cytomegalovirus infection: prospective study of 237 pregnancies at risk," Obstetrics and Gynecology, vol. 95, no. 6, pp. 881$888,2000$.

[60] D. B. DiGiulio, R. Romero, H. P. Amogan et al., "Microbial prevalence, diversity and abundance in amniotic fluid during preterm labor: a molecular and culture-based investigation," PLoS ONE, vol. 3, no. 8, Article ID e3056, 2008.

[61] K. L. B. Reddick, R. Jhaveri, M. Gandhi, A. H. James, and G. K. Swamy, "Pregnancy outcomes associated with viral hepatitis," Journal of Viral Hepatitis, vol. 18, no. 7, pp. e394-e398, 2011.

[62] H. Koi, J. Zhang, and S. Parry, "The mechanisms of placental viral infection," Annals of the New York Academy of Sciences, vol. 943, pp. 148-156, 2001.

[63] V. Ilievski, S. J. Lu, and E. Hirsch, "Activation of toll-like receptors 2 or 3 and preterm delivery in the mouse," Reproductive Sciences, vol. 14, no. 4, pp. 315-320, 2007.

[64] N. H. Hillman, T. J. M. Moss, I. Nitsos et al., "Toll-like receptors and agonist responses in the developing fetal sheep lung," Pediatric Research, vol. 63, no. 4, pp. 388-393, 2008.

[65] V. Agrawal and E. Hirsch, "Intrauterine infection and preterm labor," Seminars in Fetal \& Neonatal Medicine, vol. 17, pp. 12-19, 2012.

[66] U. Holmlund, G. Cebers, A. R. Dahlfors et al., "Expression and regulation of the pattern recognition receptors Toll-like receptor- 2 and Toll-like receptor- 4 in the human placenta," Immunology, vol. 107, no. 1, pp. 145-151, 2002.

[67] R. Romero, R. Gomez, F. Ghezzi et al., "A fetal systemic inflammatory response is followed by the spontaneous onset of preterm parturition," American Journal of Obstetrics and Gynecology, vol. 179, no. 1, pp. 186-193, 1998.

[68] C. A. Van Meir, M. M. Ramirez, S. G. Matthews, A. A. Calder, M. J. N. C. Keirse, and J. R. G. Challis, "Chorionic prostaglandin catabolism is decreased in the lower uterine segment with term labour," Placenta, vol. 18, no. 2-3, pp. 109-114, 1997.
[69] B. H. Yoon, R. Romero, J. K. Jun et al., "An increase in fetal plasma cortisol but not dehydroepiandrosterone sulfate is followed by the onset of preterm labor in patients with preterm premature rupture of the membranes," American Journal of Obstetrics and Gynecology, vol. 179, no. 5, pp. 1107-1114, 1998.

[70] D. Rezeberga, G. Lazdane, J. Kroica, L. Sokolova, and G. G. G. Donders, "Placental histological inflammation and reproductive tract infections in a low risk pregnant population in Latvia," Acta Obstetricia et Gynecologica Scandinavica, vol. 87, no. 3, pp. 360-365, 2008.

[71] R. Romero, J. Espinoza, L. F. Gonçalves, J. P. Kusanovic, L. Friel, and S. Hassan, "The role of inflammation and infection in preterm birth," Seminars in Reproductive Medicine, vol. 25, no. 1, pp. 21-39, 2007.

[72] R. Romero, J. Espinoza, L. F. Goncalves et al., "Fetal cardiac dysfunction in preterm premature rupture of membranes," The Journal of Maternal-Fetal \& Neonatal Medicine, vol. 16, pp. 146157, 2004.

[73] M. M. Parker, J. H. Shelhamer, and S. L. Bacharach, "Profound but reversible myocardial depression in patients with septic shock," Annals of Internal Medicine, vol. 100, no. 4, pp. 483-490, 1984.

[74] T. D. Yanowitz, J. A. Jordan, C. H. Gilmour et al., "Hemodynamic disturbances in premature infants born after chorioamnionitis: association with cord blood cytokine concentrations," Pediatric Research, vol. 51, no. 3, pp. 310-316, 2002.

[75] S. Rounioja, J. Räsänen, V. Glumoff, M. Ojaniemi, K. Mäkikallio, and M. Hallman, "Intra-amniotic lipopolysaccharide leads to fetal cardiac dysfunction: a mouse model for fetal inflammatory response," Cardiovascular Research, vol. 60, no. 1, pp. 156-164, 2003.

[76] M. A. Panaro, A. Acquafredda, P. Cavallo, A. Cianciulli, C. Saponaro, and V. Mitolo, "Inflammatory responses in embryonal cardiomyocytes exposed to LPS challenge. An in vitro model of deciphering the effects of LPS on the heart," Current Pharmaceutical Design, vol. 16, no. 7, pp. 754-765, 2010.

[77] K. L. Watterberg, L. M. Demers, S. M. Scott, and S. Murphy, "Chorioamnionitis and early lung inflammation in infants in whom bronchopulmonary dysplasia develops," Pediatrics, vol. 97, no. 2, pp. 210-215, 1996.

[78] A. J. Westover and T. J. Moss, "Effects of intrauterine infection/inflammation on fetal lung development," Clinical and Experimental Pharmacology \& Physiology, vol. 39, no. 9, pp. 824-830, 2012.

[79] D. J. Henderson-Smart, J. L. Hutchinson, D. A. Donoghue, N. J. Evans, J. M. Simpson, and I. Wright, "Prenatal predictors of chronic lung disease in very preterm infants," Archives of Disease in Childhood, vol. 91, no. 1, pp. F40-F45, 2006.

[80] A. H. Jobe and M. Ikegami, "Prevention of bronchopulmonary dysplasia," Current Opinion in Pediatrics, vol. 13, no. 2, pp. 124129, 2001.

[81] J. V. Been, I. G. Rours, R. F. Kornelisse, F. Jonkers, R. R. de Krijger, and L. J. Zimmermann, "Chorioamnionitis alters the response to surfactant in preterm infants," Journal of Pediatrics, vol. 156, no. 1, pp. 10.e1-15.el, 2010.

[82] H. J. Lee, E. K. Kim, H. S. Kim, C. W. Choi, B. I. I. Kim, and J. H. Choi, "Chorioamnionitis, respiratory distress syndrome and bronchopulmonary dysplasia in extremely low birth weight infants," Journal of Perinatology, vol. 31, no. 3, pp. 166-170, 2011.

[83] M. Laughon, E. N. Allred, C. Bose et al., "Patterns of respiratory disease during the first 2 postnatal weeks in extremely premature infants," Pediatrics, vol. 123, no. 4, pp. 1124-1131, 2009. 
[84] A. H. Jobe, “The new bronchopulmonary dysplasia," Current Opinion in Pediatrics, vol. 23, no. 2, pp. 167-172, 2011.

[85] T. Ikegami, A. Tsuda, A. Karube, H. Kodama, H. Hirano, and T. Tanaka, "Effects of intrauterine IL-6 and IL-8 on the expression of surfactant apoprotein mRNAs in the fetal rat lung," European Journal of Obstetrics Gynecology and Reproductive Biology, vol. 93, no. 1, pp. 97-103, 2000.

[86] L. S. Prince, V. O. Okoh, T. O. Moninger, and S. Matalon, "Lipopolysaccharide increases alveolar type II cell number in fetal mouse lungs through Toll-like receptor 4 and NF- $\kappa \mathrm{B}$," American Journal of Physiology, vol. 287, no. 5, pp. L999-L1006, 2004.

[87] K. Bry, U. Lappalainen, and M. Hallman, "Intraamniotic interleukin-1 accelerates surfactant protein synthesis in fetal rabbits and improves lung stability after premature birth," Journal of Clinical Investigation, vol. 99, no. 12, pp. 2992-2999, 1997.

[88] K. E. Willet, A. H. Jobe, M. Ikegami, J. Newnham, S. Brennan, and P. D. Sly, "Antenatal endotoxin and glucocorticoid effects on lung morphometry in preterm lambs," Pediatric Research, vol. 48, no. 6, pp. 782-788, 2000.

[89] T. J. M. Moss, J. P. Newnham, K. E. Willett, B. W. Kramer, A. H. Jobe, and M. Ikegami, "Early gestational intra-amniotic endotoxin: lung function, surfactant, and morphometry," American Journal of Respiratory and Critical Care Medicine, vol. 165, no. 6, pp. 805-811, 2002.

[90] A. J. Westover, S. B. Hooper, M. J. Wallace, and T. J. Moss, "Prostaglandins mediate the fetal pulmonary response to intrauterine inflammation," American Journal of Physiology Lung Cellular and Molecular Physiology, vol. 302, pp. L664L678, 2012.

[91] S. G. Kallapur, A. H. Jobe, M. Ikegami, and C. J. Bachurski, "Increased IP-10 and MIG expression after intra-amniotic endotoxin in preterm lamb lung," American Journal of Respiratory and Critical Care Medicine, vol. 167, no. 5, pp. 779-786, 2003.

[92] S. G. Kallapur, C. J. Bachurski, T. D. Le Cras, S. N. Joshi, M. Ikegami, and A. H. Jobe, "Vascular changes after intraamniotic endotoxin in preterm lamb lungs," American Journal of Physiology, vol. 287, no. 6, pp. L1178-L1185, 2004.

[93] R. Galinsky, S. B. Hooper, G. R. Polglase, and T. J. M. Moss, "Intrauterine inflammation alters fetal cardiopulmonary and cerebral hemodynamics in sheep," In Press.

[94] M. Woldesenbet and J. M. Perlman, "Histologic chorioamnionitis: an occult marker of severe pulmonary hypertension in the term newborn," Journal of Perinatology, vol. 25, no. 3, pp. 189192, 2005.

[95] S. H. Abman, "Recent advances in the pathogenesis and treatment of persistent pulmonary hypertension of the newborn," Neonatology, vol. 91, no. 4, pp. 283-290, 2007.

[96] R. H. Steinhorn, "Neonatal pulmonary hypertension," Pediatric Critical Care Medicine, vol. 11, no. 2, pp. S79-S84, 2010.

[97] G. R. Polglase, S. B. Hooper, A. W. Gill et al., "Intrauterine inflammation causes pulmonary hypertension and cardiovascular sequelae in preterm lambs," Journal of Applied Physiology, vol. 108, no. 6, pp. 1757-1765, 2010.

[98] G. R. Polglase, I. Nitsos, A. A. Baburamani et al., "Inflammation in utero exacerbates ventilation-induced brain injury in preterm lambs," Journal of Applied Physiology, vol. 112, pp. 481-489, 2012.

[99] T. Kaukola, R. Herva, M. Perhomaa et al., "Population cohort associating chorioamnionitis, cord inflammatory cytokines and neurologic outcome in very preterm, extremely low birth weight infants," Pediatric Research, vol. 59, no. 3, pp. 478-483, 2006.
[100] R. W. Redline, N. Minich, H. G. Taylor, and M. Hack, "Placental lesions as predictors of cerebral palsy and abnormal neurocognitive function at school age in extremely low birth weight infants $(<1 \mathrm{~kg})$," Pediatric and Developmental Pathology, vol. 10, no. 4, pp. 282-292, 2007.

[101] A. Suppiej, M. Franzoi, S. Vedovato, A. Marucco, S. Chiarelli, and V. Zanardo, "Neurodevelopmental outcome in preterm histological chorioamnionitis," Early Human Development, vol. 85 , no. 3, pp. 187-189, 2009.

[102] CDC, "Economic costs associated with mental retardation, cerebral palsy, hearing loss, and vision impairment-United States, 2003," MMWR Morbidity and Mortality Weekly Report, vol. 53, pp. 57-59, 2004.

[103] Y. W. Wu, "Systematic review of chorioamnionitis and cerebral palsy," Mental Retardation and Developmental Disabilities Research Reviews, vol. 8, no. 1, pp. 25-29, 2002.

[104] D. J. Murphy, S. Sellers, I. Z. MacKenzie, P. L. Yudkin, and A. M. Johnson, "Case-control study of antenatal and intrapartum risk factors for cerebral palsy in very preterm singleton babies," The Lancet, vol. 346, no. 8988, pp. 1449-1454, 1995.

[105] J. K. Grether and K. B. Nelson, "Maternal infection andcerebral palsy in infants of normal birth weight," Journal of the American Medical Association, vol. 278, no. 3, pp. 207-211, 1997.

[106] J. K. Grether and K. B. Nelson, "Erratum: maternal infection and cerebral palsy in infants of normal birth weight," Journal of the American Medical Association, vol. 279, no. 2, p. 118, 1998.

[107] I. Hansen-Pupp, A. L. Hallin, L. Hellström-Westas et al., "Inflammation at birth is associated with subnormal development in very preterm infants," Pediatric Research, vol. 64, no. 2, pp. 183-188, 2008.

[108] O. Khwaja and J. J. Volpe, "Pathogenesis of cerebral white matter injury of prematurity," Archives of Disease in Childhood, vol. 93, no. 2, pp. F153-F161, 2008.

[109] C. Limperopoulos, H. Bassan, N. R. Sullivan et al., "Positive screening for autism in ex-preterm infants: prevalence and risk factors," Pediatrics, vol. 121, no. 4, pp. 758-765, 2008.

[110] A. S. Brown, J. Hooton, C. A. Schaefer et al., "Elevated maternal interleukin-8 levels and risk of schizophrenia in adult offspring," American Journal of Psychiatry, vol. 161, no. 5, pp. 889-895, 2004.

[111] A. S. Brown, "The environment and susceptibility to schizophrenia," Progress in Neurobiology, vol. 93, no. 1, pp. 23-58, 2010.

[112] U. Meyer, J. Feldon, and O. Dammann, "Schizophrenia and autism: both shared and disorder-specific pathogenesis via perinatal inflammation?" Pediatric Research, vol. 69, no. 5, pp. 26R-33R, 2011.

[113] Y. W. Wu and J. M. Colford, "Chorioamnionitis as a risk factor for cerebral palsy: a meta-analysis," Journal of the American Medical Association, vol. 284, no. 11, pp. 1417-1424, 2000.

[114] R. Romero, J. Espinoza, L. F. Gonçalves et al., "Fetal cardiac dysfunction in preterm premature rupture of membranes," Journal of Maternal-Fetal and Neonatal Medicine, vol. 16, no. 3, pp. 146-157, 2004.

[115] T. D. Yanowitz, R. W. Baker, J. M. Roberts, and B. S. Brozanski, "Low blood pressure among very-low-birth-weight infants with fetal vessel inflammation," Journal of Perinatology, vol. 24, no. 5, pp. 299-304, 2004.

[116] T. D. Yanowitz, J. A. Jordan, C. H. Gilmour et al., "Hemodynamic disturbances in premature infants born after chorioamnionitis: association with cord blood cytokine concentrations," Pediatric Research, vol. 51, no. 3, pp. 310-316, 2002. 
[117] T. D. Yanowitz, D. M. Potter, A. Bowen, R. W. Baker, and J. M. Roberts, "Variability in cerebral oxygen delivery is reduced in premature neonates exposed to chorioamnionitis," Pediatric Research, vol. 59, no. 2, pp. 299-304, 2006.

[118] O. Khwaja and J. J. Volpe, "Pathogenesis of cerebral white matter injury of prematurity," Archives of Disease in Childhood, vol. 93, no. 2, pp. F153-F161, 2008.

[119] T. D. Yanowitz, "Cerebrovascular autoregulation among very low birth weight infants," Journal of Perinatology, vol. 31, pp. 689-691, 2011.

[120] J. S. Soul, P. E. Hammer, M. Tsuji et al., "Fluctuating pressurepassivity is common in the cerebral circulation of sick premature infants," Pediatric Research, vol. 61, no. 4, pp. 467-473, 2007.

[121] M. M. Gilmore, B. S. Stone, J. A. Shepard et al., "Relationship between cerebrovascular dysautoregulation and arterial blood pressure in the premature infant," Journal of Perinatology, vol. 31, pp. 722-729, 2011.

[122] T. D. Yanowitz, R. W. Baker, and J. M. Roberts, "Hemodynamic changes in premature infants exposed to chorioamnionitis," Pediatric Research, vol. 55, pp. 524A-524A, 2004.

[123] C. Limperopoulos, K. K. Gauvreau, H. O’Leary et al., "Cerebral hemodynamic changes during intensive care of preterm infants," Pediatrics, vol. 122, no. 5, pp. e1006-e1013, 2008.

[124] B. H. Yoon, C. J. Kim, R. Romero et al., "Experimentally induced intrauterine infection causes fetal brain white matter lesions in rabbits," American Journal of Obstetrics and Gynecology, vol. 177, no. 4, pp. 797-802, 1997.

[125] I. Nitsos, S. M. Rees, J. Duncan et al., "Chronic exposure to intra-amniotic lipopolysaccharide affects the ovine fetal brain," Journal of the Society for Gynecologic Investigation, vol. 13, no. 4, pp. 239-247, 2006.

[126] J. R. Duncan, M. L. Cock, K. Suzuki, J. P. Y. Scheerlinck, R. Harding, and S. M. Rees, "Chronic endotoxin exposure causes brain injury in the ovine fetus in the absence of hypoxemia," Journal of the Society for Gynecologic Investigation, vol. 13, no. 2, pp. 87-96, 2006.

[127] Z. Cai, Z. L. Pan, Y. Pang, O. B. Evans, and P. G. Rhodes, "Cytokine induction in fetal rat brains and brain injury in neonatal rats after maternal lipopolysaccharide administration," Pediatric Research, vol. 47, no. 1, pp. 64-72, 2000.

[128] C. C. Andersen, J. J. Pillow, A. W. Gill et al., "The cerebral critical oxygen threshold of ventilated preterm lambs and the influence of antenatal inflammation," Journal of Applied Physiology, vol. 111, pp. 775-781, 2011.

[129] A. Leviton, "Preterm birth and cerebral palsy: is tumor necrosis factor the missing link?" Developmental Medicine and Child Neurology, vol. 35, no. 6, pp. 553-558, 1993.

[130] B. H. Yoon, R. Romero, J. K. Jun et al., "Amniotic fluid cytokines (interleukin-6, tumor necrosis factor- $\alpha$, interleukin$1 \beta$, and interleukin-8) and the risk for the development of bronchopulmonary dysplasia," American Journal of Obstetrics and Gynecology, vol. 177, no. 4, pp. 825-830, 1997.

[131] K. Iida, S. Takashima, and Y. Takeuchi, "Etiologies and distribution of neonatal leukomalacia," Pediatric Neurology, vol. 8, no. 3, pp. 205-209, 1992.

[132] T. van der Poll, H. R. Buller, H. Ten Cate et al., "Activation of coagulation after administration of tumor necrosis factor to normal subjects," The New England Journal of Medicine, vol. 322, no. 23, pp. 1622-1627, 1990.

[133] K. W. Selmaj and C. S. Raine, "Tumor necrosis factor mediates myelin and oligodendrocyte damage in vitro," Annals of Neurology, vol. 23, no. 4, pp. 339-346, 1988.
[134] A. W. D. Gavilanes, E. Strackx, B. W. Kramer et al., "Chorioamnionitis induced by intraamniotic lipopolysaccharide resulted in an interval-dependent increase in central nervous system injury in the fetal sheep," American Journal of Obstetrics and Gynecology, vol. 200, no. 4, pp. 437.e1-437.e8, 2009.

[135] A. Leviton and P. Gressens, "Neuronal damage accompanies perinatal white-matter damage," Trends in Neurosciences, vol. 30, no. 9, pp. 473-478, 2007.

[136] M. Gantert, J. V. Been, A. W. Gavilanes et al., "Chorioamnionitis: a multiorgan disease of the fetus?" Journal of Perinatology, vol. 30, pp. S21-S30, 2010.

[137] B. H. Yoon, J. K. Jun, R. Romero et al., "Amniotic fluid inflammatory cytokines (interleukin-6, interleukin-1 $\beta$, and tumor necrosis factor- $\alpha$ ), neonatal brain white matter lesions, and cerebral palsy," American Journal of Obstetrics and Gynecology, vol. 177, no. 1, pp. 19-26, 1997.

[138] M. K. Sharief and E. J. Thompson, "In vivo relationship of tumor necrosis factor- $\alpha$ of blood-brain barrier damage in patients with active multiple sclerosis," Journal of Neuroimmunology, vol. 38, no. 1-2, pp. 27-34, 1992.

[139] D. Wong, K. Dorovini-Zis, and S. R. Vincent, "Cytokines, nitric oxide, and cGMP modulate the permeability of an in vitro model of the human blood-brain barrier," Experimental Neurology, vol. 190, no. 2, pp. 446-455, 2004.

[140] F. Moscuzza, F. Belcari, V. Nardini et al., "Correlation between placental histopathology and fetal/neonatal outcome: chorioamnionitis and funisitis are associated to intraventricular haemorrage and retinopathy of prematurity in preterm newborns," Gynecological Endocrinology, vol. 27, no. 5, pp. 319-323, 2011.

[141] S. Polam, A. Koons, M. Anwar, S. Shen-Schwarz, and T. Hegyi, "Effect of chorioamnionitis on neurodevelopmental outcome in preterm infants," Archives of Pediatrics and Adolescent Medicine, vol. 159, no. 11, pp. 1032-1035, 2005.

[142] M. Sato, S. Nishimaki, S. Yokota et al., "Severity of chorioamnionitis and neonatal outcome," Thejournal of Obstetrics and Gynaecology Research, vol. 37, pp. 1313-1319, 2011.

[143] J. Lee and O. Dammann, "Perinatal infection, inflammation, and retinopathy of prematurity," Seminars in Fetal \& Neonatal Medicine, vol. 17, pp. 26-29, 2012.

[144] P. M. Liu, P. C. Fang, C. B. Huang et al., "Risk factors of retinopathy of prematurity in premature infants weighing less than 1600 g," American Journal of Perinatology, vol. 22, no. 2, pp. 115-120, 2005.

[145] J. M. Di Fiore, J. N. Bloom, F. Orge et al., "A higher incidence of intermittent hypoxemic episodes is associated with severe retinopathy of prematurity," Journal of Pediatrics, vol. 157, no. 1, pp. 69-73, 2010.

[146] B. H. Yoon, Y. A. Kim, R. Romero et al., "Association of oligohydramnios in women with preterm premature rupture of membranes with an inflammatory response in fetal, amniotic, and maternal compartments," American Journal of Obstetrics and Gynecology, vol. 181, no. 4, pp. 784-788, 1999.

[147] M. S. Rangel-Frausto, D. Pittet, M. Costigan, T. Hwang, C. S. Davis, and R. P. Wenzel, "The natural history of the systemic inflammatory response syndrome (SIRS): a prospective study," Journal of the American Medical Association, vol. 273, no. 2, pp. 117-123, 1995.

[148] A. B. Modena and S. Fieni, "Amniotic fluid dynamics," Acta Biomedica de l'Ateneo Parmense, vol. 75, no. 1, pp. 11-13, 2004.

[149] K. Itabashi, T. Ohno, and H. Nishida, "Indomethacin responsiveness of patent ductus arteriosus and renal abnormalities 
in preterm infants treated with indomethacin," Journal of Pediatrics, vol. 143, no. 2, pp. 203-207, 2003.

[150] R. Galinsky, T. J. M. Moss, L. Gubhaju, S. B. Hooper, M. Jane Black, and G. R. Polglase, "Effect of intra-amniotic lipopolysaccharide on nephron number in preterm fetal sheep," American Journal of Physiology, vol. 301, no. 2, pp. F280-F285, 2011.

[151] B. M. Brenner, D. L. Garcia, and S. Anderson, "Glomeruli and blood pressure. Less of one, more the other?" American Journal of Hypertension, vol. 1, no. 4, pp. 335-347, 1988. 


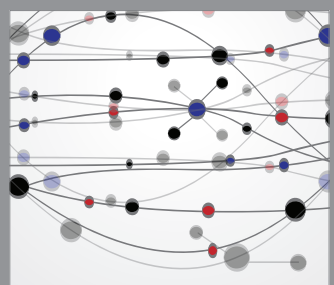

The Scientific World Journal
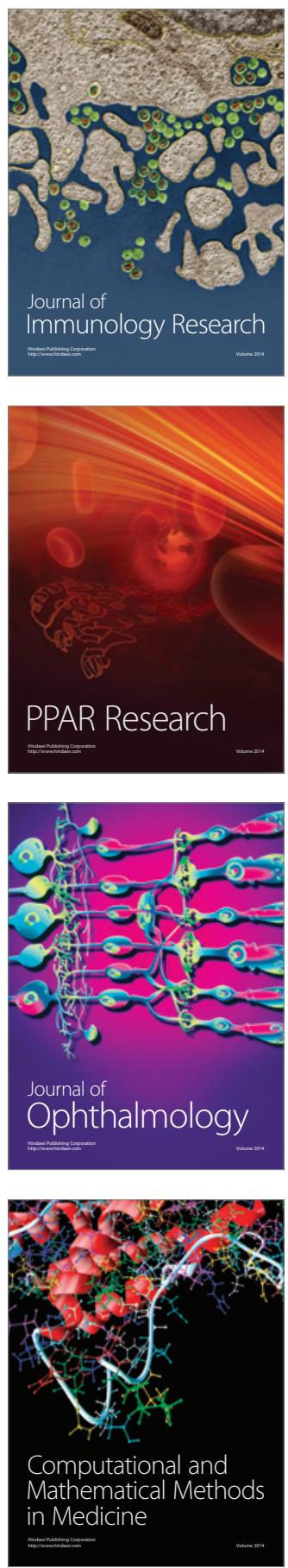

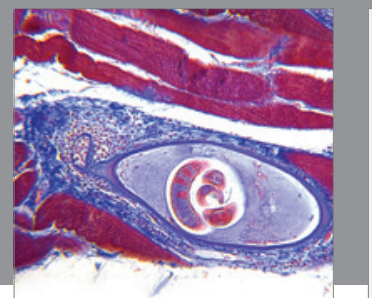

Gastroenterology

Research and Practice
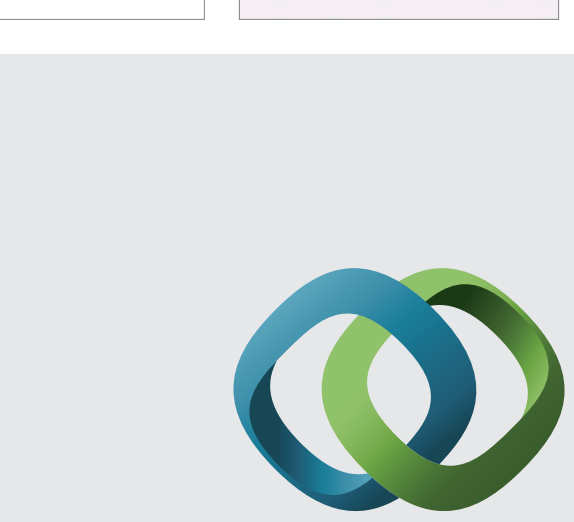

\section{Hindawi}

Submit your manuscripts at

http://www.hindawi.com
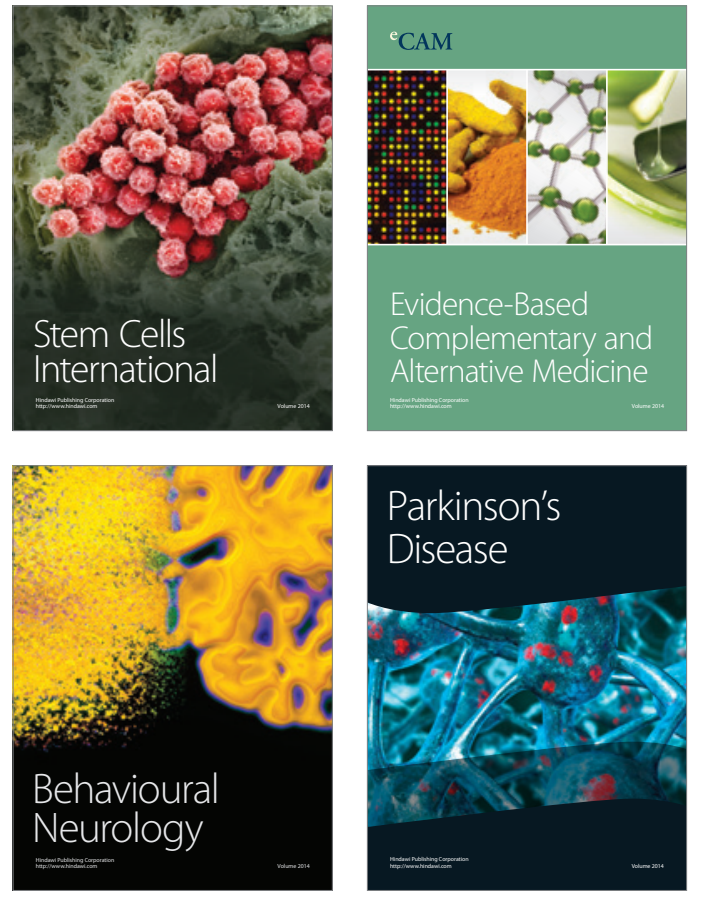
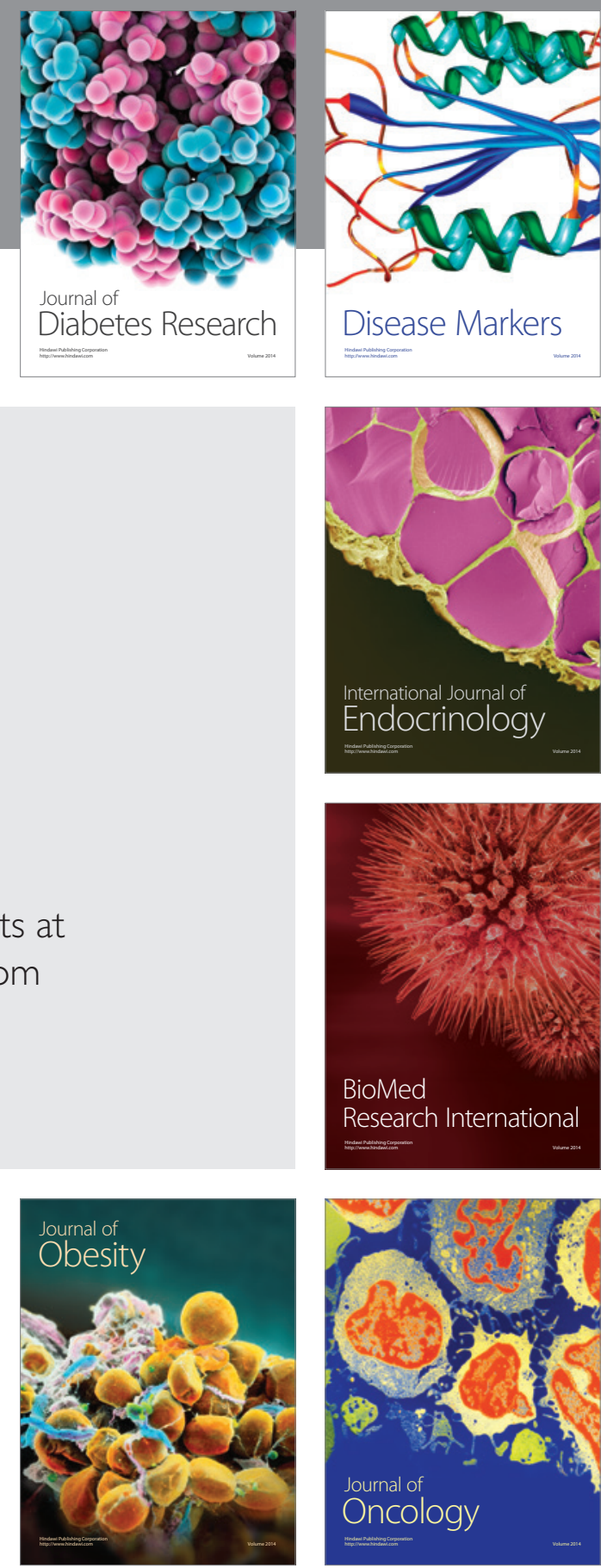

Disease Markers
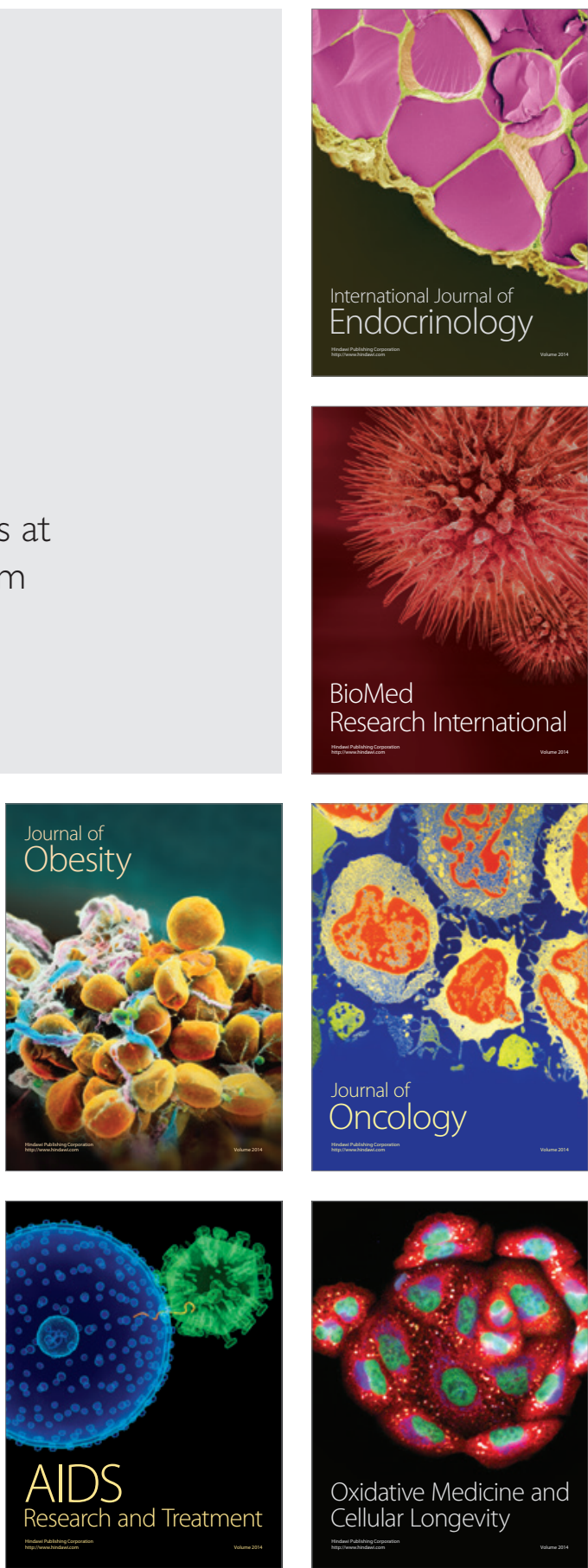